\title{
Pricing and Coordination Mechanism of Supply Chain considering Product Recycling under Asymmetric Power
}

\author{
Hangxin Guo $\mathbb{D}^{1},{ }^{1}$ Zheng Liu $\mathbb{D}^{1},{ }^{1}$ Bin Hu, ${ }^{1}$ Huidan Lin, ${ }^{2}$ Lihua Shi, ${ }^{1}$ and Cuicui Meng ${ }^{1}$ \\ ${ }^{1}$ School of Management, Shanghai University of Engineering Science, Shanghai, China \\ ${ }^{2}$ School of Economics \& Management, Shanghai Polytechnic University, Shanghai, China \\ Correspondence should be addressed to Zheng Liu; liuzheng960@163.com
}

Received 21 January 2021; Revised 18 February 2021; Accepted 8 March 2021; Published 18 March 2021

Academic Editor: Xiaobo Qu

Copyright ( 2021 Hangxin Guo et al. This is an open access article distributed under the Creative Commons Attribution License, which permits unrestricted use, distribution, and reproduction in any medium, provided the original work is properly cited.

The concept of "green supply chain" puts forward new requirements for the recycling management of waste products. The waste electronic products are taken as the research object, and a two-stage closed-loop supply chain composed of a manufacturer, a retailer, and consumers is considered in this paper. By constructing a Stackelberg game model, the pricing strategy and profit distribution of the supply chain under different decision modes considering asymmetric powers are studied. Finally, Python is used for simulation. The results show that the gross profit of supply chain under decentralized decision is always lower than that under centralized decision-making, and asymmetric power has an impact on the pricing decision-making of forward supply chain and reverse supply chain; compared with transfer cost, wholesale price has a greater impact on coordination effect.

\section{Introduction}

With the increasingly serious environmental problems, people's awareness of environmental protection has been strengthened, and the value of reverse supply chain has also been revealed [1]. Through the recycling of waste products, manufacturers not only benefit the economic sustainability but also reduce the unit cost of products and increase the income. Due to the differences of enterprise scale, game ability, and other conditions, the power asymmetry between the main bodies of the supply chain will affect the decisionmaking behavior of the main bodies of the supply chain and indirectly affect the total profit and profit distribution of the supply chain. Many scholars have studied the optimization decision and coordination mechanism of supply chain.

Liao et al. considered the uncertainty of consumer value and demand in remanufacturing closed-loop supply chain, analyzed market demand by introducing utility function, and studied the optimal pricing strategy and channel strategy by using game theory [2]. Liu et al. studied the optimization of dual-channel low-carbon supply chain by constructing the double objective function of environment and economy [3]. Yang et al. studied the coordination problem of closed-loop supply chain under stochastic demand when the supply chain is dominated by retailers [4]. Zhao et al. studied the pricing strategy of closed-loop supply chain under the mixed recycling channel when the government subsidizes different objects. The results show that when the government subsidizes different objects for consumers or retailers, the pricing index is higher [5]. Zhu et al. studied the optimal pricing strategy under different decision models by considering the manufacturability ratio of recycled products and the difference of recycling costs among different recyclers [6]. Zheng et al. studied the influence of different social responsibility input behaviors of supply chain members on supply chain pricing strategy. Finally, the supply chain was coordinated by two-tariff contract [7]. Yao et al. considered the behavior characteristics of decision-makers in the supply chain system and studied the impact of retailers' fair concern behavior on supply chain decision-making [8]. Haddadsisakht et al. considered the uncertainty of stochastic demand and carbon tax rate and studied the transportation network equilibrium of closed-loop supply chain [9]. Modak et al. considered the influence of product quality on demand and studied the pricing strategy of closed-loop supply chain [10]. 
Sahebjamnia et al. optimized the closed-loop supply chain by establishing a multiobjective mixed-integer linear programming model and used metaheuristic algorithm for solution [11]. Liu et al. studied a more reasonable bus pricing strategy based on the different characteristics of different groups [12]. According to different pricing structure and competition behavior, Lee studied the optimal pricing strategy of closed-loop supply chain. The research shows that the total profit of supply chain is positively correlated with the recovery rate [13]. Based on the perishable characteristics of fresh agricultural products, Liu et al. studied the cold chain logistics path optimization problem with time window [14].

Li et al. studied the influence of asymmetric powers on supply chain decision-making and performance [15]. Gao et al. studied the influence of asymmetric power on remanufacturer's technological innovation strategy by using the Stackelberg model. The results show that when the innovation efficiency is high, the innovation level is higher when the remanufacturer dominates the supply chain [16]. $\mathrm{Li}$ et al. considered the free riding behavior of consumers and studied the influence of free riding periods on supply chain decision-making. The results show that the price of direct marketing channel is positively correlated with free riding coefficient [17]. Fan et al. considered the low-carbon preference of consumers in the secondary supply chain and studied the optimal carbon emission reduction policies of enterprises under asymmetric powers. The results show that corporate carbon emission reduction strategy is not affected by power structure [18]. Taleizadeh et al. studied the optimal strategies of quality level and hard decision of closed-loop supply chain in the case of third-party Stackelberg game based on the traditional research on power structure [19]. Lee et al. studied the optimal strategy for enterprises to implement innovation strategy under asymmetric powers. The research shows that no matter what kind of power structure, market leaders should promote green innovation strategy [20]. Ranjbar et al. considered the closed-loop supply chain with multichannel recycling and analyzed the influence of asymmetric power on the recovery strategy and pricing strategy by building a game model. The results show that the retailer-dominated supply chain is closest to the centralized decision model [21].

To sum up, many scholars have studied the pricing and coordination strategies of closed-loop supply chain and the influence of asymmetric power on the behavior decisionmaking of supply chain. Few scholars consider power structure and dual-channel recycling at the same time. From this point of view, this paper takes waste electronic products as the research object, considers the two-level closed-loop supply chain composed of a manufacturer, a retailer, and consumers, and studies the pricing strategy and profit distribution of supply chain under centralized decisionmaking mode and decentralized decision-making mode considering asymmetric powers. The supply chain is coordinated by two-tariff contract and finally analyzed by numerical simulation. Through the research on pricing strategy and coordination mechanism of dual-channel closed-loop supply chain under asymmetric power, this paper combines corporate social responsibility with power structure, explores the role of power structure on game equilibrium solution, enriches the research on corporate social responsibility in green supply chain to a certain extent, and provides ideas for supply chain management of reverse supply chain.

\section{Problem Description and Hypothesis}

In this paper, waste electronic products are taken as the research object, and a two-level closed-loop supply chain system composed of a manufacturer, a retailer, and consumers is considered. The specific operation mode of the supply chain is shown in Figure 1.

Hypothesis 1. The manufacturer of electronic products can produce new materials or recycled and processed materials of waste products, and the costs of producing equal-quality products in two cases are $c_{1}$ and $c_{2}$, respectively. Therefore, the unit cost saving of manufacturer for product remanufacturing is $\delta=c_{1}-c_{2}$, and it is assumed that consumers have no preference difference for the products produced by the two materials.

Hypothesis 2. The wholesale price of the retailer is $\omega$ and the retail price is $p$. In the recycling stage, the retailer recycles the product from the consumer at the price of $p_{1}$, and the manufacturer recycles the product from the retailer at the price of $p_{2}$. In order to ensure that the middleman has a favorable graph, assume $p>\omega, p_{2}>p_{1}$.

Hypothesis 3. Suppose that the demand function of the product in the sales stage is $Q=a-b p+u$, where $a$ is the market capacity, $b$ is the price elasticity of demand, and $\mu$ is the random demand, which is uniformly distributed in $[\varphi, \chi] ; E(u)=\mu$.

Hypothesis 4. Since there is competition between the two channels in the recycling stage, it is assumed that the recycling demand functions of the retailer and the manufacturer are, respectively, $q_{1}=\lambda c+d p_{1}+\beta\left(p_{1}-p_{3}\right), q_{2}$ $=(1-\lambda) c+d p_{3}+\beta\left(p_{3}-p_{1}\right)$, where $\lambda$ is the channel competition coefficient, $c$ is the basic recycling volume, $d$ is the consumer's sensitivity coefficient to the recycling price, and $\beta$ is the sensitive coefficient of the consumer's price difference in different channels. It is assumed that the unit recovery cost of direct recycler is $t$.

\section{Model Establishment and Solution}

Based on the above assumptions, the expected profits of manufacturers and retailers are as follows:

$$
\begin{aligned}
& E\left(\Pi_{1}\right)=\left(\omega-c_{1}\right) Q+\left(\delta-p_{2}\right) q_{1}+\left(\delta-p_{3}\right) q_{2}-t q_{2}, \\
& E\left(\Pi_{2}\right)=(p-\omega) Q+\left(p_{2}-p_{1}\right) q_{1}-t q_{1} .
\end{aligned}
$$

According to the relationship among members of supply chain, the decision-making methods can be divided into centralized decision-making and decentralized decision- 


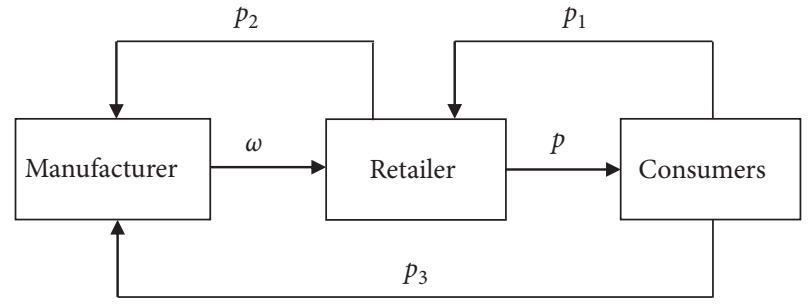

FIGURE 1: Operation mode of two-level supply chain.

making. When the members of the supply chain make centralized decisions, they pursue the maximum of the total profit of the supply chain, which reflects a cooperative relationship. When the members of the supply chain make decentralized decisions, they pursue the maximization of their profits, which reflects a competitive relationship. Therefore, we will model and solve different decision patterns.

3.1. Centralized Decision Model (Type C). When the supply chain system makes centralized decision, the goal is to maximize the total profit of the supply chain system. Therefore, the expected function of total profit of supply chain is constructed as follows:

$$
E(\Pi)=\left(p-c_{1}\right) Q+\left(\delta-p_{1}-t\right) q_{1}+\left(\delta-p_{3}-t\right) q_{2} .
$$

In order to determine the optimal retail price $p$ and the recycling price $p_{1}$, the first derivative of $E(\Pi)$ with respect to $p, p_{1}$, and $p_{3}$ is obtained as follows:

$$
\left\{\begin{array}{l}
\frac{\partial E(\Pi)}{\partial p}=a-b p+b\left(c_{1}-p\right)+\mu=0 \\
\frac{\partial E(\Pi)}{\partial p_{1}}=-c \lambda+\delta d-2 d p_{1}-d t-2 \beta\left(p_{1}-p_{3}\right)=0 \\
\frac{\partial E(\Pi)}{\partial p_{3}}=c(\lambda-1)+\delta d-2 d p_{3}-d t+2 \beta\left(p_{1}-p_{3}\right)=0
\end{array}\right.
$$

and the corresponding Hessian matrix is as follows:

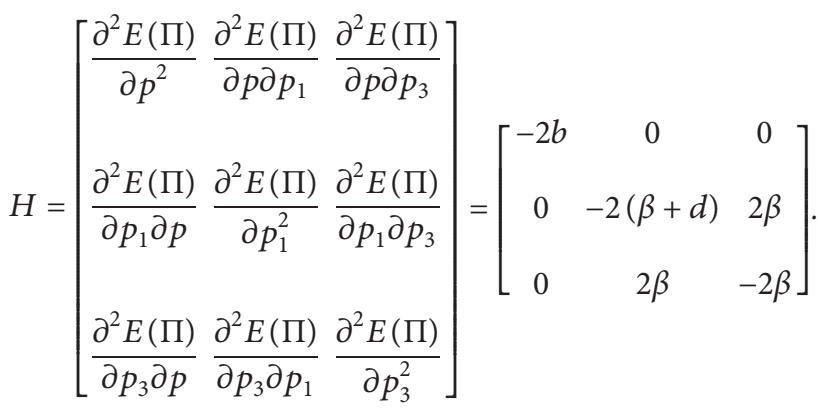

Because of $-2 b<0,\left|\begin{array}{cc}-2 b & 0 \\ 0 & -2(\beta+d)\end{array}\right|=4 b(\beta+d)>0$, and $|H|=-8 b \beta d<0$, the Hessian matrix is strictly negative definite; that is, the total profit function of the supply chain is a strictly joint concave function of $p$ and $p_{3}$. Therefore, there is a unique optimal retail price $p$ and recycling price $p_{1}, p_{3}$ to maximize the total profit of the supply chain. Let the first derivative of $E(\Pi)$ with respect to $p, p_{1}$ and $p_{3}$ be 0 :

$$
\left\{\begin{array}{l}
p^{C}=\frac{a+b c_{1}+\mu}{2 b}, \\
p_{1}^{C}=\frac{\beta(c \lambda-c+\delta d-d t)-(d+\beta)(c \lambda-\delta d+d t)}{2 d(d+2 \beta)}, \\
p_{3}^{C}=\frac{\beta(c \lambda+\delta d+d t)-(d+\beta)(c \lambda-c+\delta d-d t)}{2 d(d+2 \beta)} .
\end{array}\right.
$$

By substituting $p^{C}, p_{1}^{C}$, and $p_{3}^{C}$ into $E\left(\Pi^{C}\right)$, the maximum expected profit of supply chain system can be obtained:

$$
\Pi^{*}=\frac{\lambda(\lambda-1) c^{2}}{2(d+2 \beta)}+\frac{c^{2}(d+\beta)}{4 d(d+2 \beta)}+\frac{\left(b c_{1}-\mu\right)^{2}+2 b c(\delta-t)+2 b d \delta(\delta-2)+a^{2}+2 a\left(\mu-b c_{1}\right)+2 b d t^{2}}{4 b}
$$

\subsection{Decentralized Decision Model}

3.2.1. Manufacturer-Led Supply Chain System (Type M). When the supply chain system is dominated by the manufacturer, the game between the manufacturer and the retailer is divided into two stages: firstly, the manufacturer decides the wholesale price $\omega$ and the recycling price $p_{2}, p_{3}$, and then the retailer decides the retail price $p$ and the recycling price $p_{1}$. Based on the inverse induction method, the first derivative of retailer's profit $E\left(\Pi_{2}\right)$ with respect to $p, p_{1}$, and $p_{3}$ is as follows: 


$$
\left\{\begin{array}{l}
\frac{\partial E\left(\Pi_{2}\right)}{\partial p}=a-b p-b(p-\omega)+\mu=0 \\
\frac{\partial E\left(\Pi_{2}\right)}{\partial p_{1}}=-\lambda c-d p_{1}-\beta\left(p_{1}-p_{3}\right) d p_{1}-(d+\beta)\left(p_{1}-p_{2}+t\right)=0
\end{array}\right.
$$

and the corresponding Hessian matrix is as follows:

$$
H=\left[\begin{array}{cc}
\frac{\partial^{2} E\left(\Pi_{2}\right)}{\partial p^{2}} & \frac{\partial^{2} E\left(\Pi_{2}\right)}{\partial p \partial p_{1}} \\
\frac{\partial^{2} E\left(\Pi_{2}\right)}{\partial p_{1} \partial p} & \frac{\partial^{2} E\left(\Pi_{2}\right)}{\partial p_{1}^{2}}
\end{array}\right]=\left[\begin{array}{cc}
-2 b & 0 \\
0 & -2(\beta+d)
\end{array}\right] .
$$

Therefore, the Hessian matrix is strictly negative definite. Therefore, the existence of unique retail price and recycling price makes the retailer's expected profit maximum. Let $\left(\partial E\left(\Pi_{2}\right) / \partial p\right)=0, \quad\left(\partial E\left(\Pi_{2}\right) / \partial p_{1}\right)=0$, and $\left(\partial E\left(\Pi_{2}\right) / \partial p_{3}\right)$ $=0$; we can obtain the optimal response function of retailer:

$$
\left\{\begin{array}{l}
p=\frac{a+b \omega+\mu}{2 b} \\
p_{1}=\frac{-\lambda c-d t+d p_{2}+\lambda\left(p_{2}+p_{3}\right)-\lambda t}{2(d+\beta)} .
\end{array}\right.
$$

By substituting $p$ and $p_{1}$ into $E\left(\Pi_{1}\right)$, the first derivative of $E\left(\Pi_{1}\right)$ with respect to $\omega$ and $p_{2}, p_{3}$ can obtain the optimal pricing decision of the retailer:

$$
\left\{\begin{array}{l}
\frac{\partial E\left(\Pi_{1}\right)}{\partial \omega}=\frac{a+b c_{1}-2 b \omega+\mu}{2}=0 \\
\frac{\partial E\left(\Pi_{2}\right)}{\partial p_{2}}=\frac{A+\left(\delta-p_{2}\right)(d+\beta)}{2}-\lambda c+\beta(\delta-t)=0 \\
\frac{\partial E\left(\Pi_{2}\right)}{\partial p_{3}}=\frac{-\beta A+\left(\beta^{2}-2 d^{2}\right)\left(p_{3}+t-\delta\right)}{2(d+\beta)}-2 \beta p_{3}+\beta\left(p_{2}-\delta\right)+2\left[c(\lambda-1)-d p_{3}\right]=0
\end{array}\right.
$$

where $A=\lambda c-d\left(p_{2}-t\right)-\beta\left(p_{1}+p_{3}-t\right)$. From simultaneous equations (9) and (10),

$$
\left\{\begin{array}{l}
\omega^{M}=\frac{a+b c_{1}+\mu}{2 b}, \\
p^{M}=\frac{3 a+b c_{1}+3 \mu}{4 b}, \\
p_{1}^{M}=\frac{d(\delta+t)-2(\lambda c+d t+\beta t)}{4(d+\beta)}+\frac{\beta(c-2 d \delta)}{4 d(d+\beta)}-\frac{\lambda d+\beta c}{4 z(d+\beta)(d+2 \beta)} \\
p_{2}^{M}=\frac{-c d(1+\lambda)+\delta d^{2}+2 \delta d \beta+d^{2} t+2 d \beta t}{2 d(d+2 \beta)}, \\
p_{3}^{M}=\frac{c d(\lambda-1)-\beta c+\delta d^{2}+2 \delta d \beta-d^{2} t-2 d \beta t}{2 d(d+2 \beta)} .
\end{array}\right.
$$


By substituting formula (11) into the profit function, the gross profit of the supply chain $E\left(\Pi^{M}\right)$ and the expected profit of the manufacturer and retailer $E\left(\Pi_{1}^{M}\right), E\left(\Pi_{2}^{M}\right)$ can be obtained.

3.2.2. Retailer-Led Supply Chain System (Type R). When the retailer dominates the supply chain, the game between the manufacturer and the retailer is divided into two stages: firstly, the retailer decides the retail price $p$ and the recycling price $p_{1}$, and then the manufacturer decides the wholesale price $\omega$ and the recycling price $p_{2}, p_{3}$.
The inverse induction method is used to solve the Stackelberg equilibrium solution. Because it cannot be judged whether the Hessian matrix of the manufacturer's profit about the wholesale price $\omega$ and the recycling price $p_{2}, p_{3}$ is strictly negative, it is impossible to judge whether the solution exists. Therefore, we introduce marginal returns $m_{1}$ and $m_{2}$ such that $p-\omega=m_{1}, p_{2}-p_{1}=m_{2}$. $p=\omega+m_{1}, p_{2}=p_{1}+m_{2}$ is substituted into the profit function of manufacturer and retailer [22]. Firstly, calculate the first derivative of $E\left(\Pi_{1}\right)$ to $\omega$ and $p_{2}$ :

$$
\left\{\begin{array}{l}
\frac{\partial E\left(\Pi_{1}\right)}{\partial \omega}=a+b\left(c_{1}-\omega\right)-b\left(m_{1}+\omega\right)+\mu=0 \\
\frac{\partial E\left(\Pi_{1}\right)}{\partial p_{2}}=-\lambda c+d\left(m_{2}-p_{2}\right)+r\left(2 p_{3}+t-\delta-p_{2}+m_{2}\right)+\left(\delta-p_{2}\right)(d+\beta)=0 \\
\frac{\partial E\left(\Pi_{2}\right)}{\partial p_{3}}=c(\lambda-1)-d p_{3}-\beta\left(\delta-p_{2}-p_{1}+p_{3}\right)-(d+\beta)\left(p_{3}+t-\delta\right)=0
\end{array}\right.
$$

the manufacturer's optimal response function can be obtained:

$$
\left\{\begin{array}{l}
\omega=\frac{a+b\left(c_{1}-p\right)+\mu}{b} \\
p_{2}=\frac{-\lambda c d-\beta c+\delta d^{2}+2 \beta \delta d-d^{2} p_{1}+2 \beta d p_{1}}{d(d+2 \beta)} \\
p_{3}=\frac{c d(\lambda-1)-\beta c+\delta d^{2}+2 \beta \delta d-d^{2} t-2 \beta d t}{2 d(d+2 \beta)}
\end{array}\right.
$$

and the optimal pricing strategy of the manufacturer and the retailer can be obtained by simultaneous equations (12) and (13):

$$
\left\{\begin{array}{l}
\omega^{R}=\frac{a+3 b c_{1}+\mu}{4 b} \\
p^{R}=\frac{3 a+b c_{1}+3 \mu}{4 b}, \\
p_{1}^{R}=\frac{-3 c d^{2} \lambda+2 \beta c(2 \lambda d+d+\beta)-\delta d^{3}-4 \beta \delta d(d+\beta)+d t(d+2 \beta)^{2}}{2(d+\beta)(d+2 \beta)} \\
p_{2}^{R}=\frac{-c d^{2} \lambda-2 \beta c(d+\beta)+\delta d(3 d+2 \beta)(d+2 \beta)+d t(d+2 \beta)^{2}}{2(d+\beta)(d+2 \beta)} \\
p_{3}^{R}=\frac{c d(\lambda-1)-\beta c+\delta d^{2}+2 \delta d \beta-d^{2} t-2 d \beta t}{2 d(d+2 \beta)}
\end{array}\right.
$$


By substituting formula (14) into the profit function, the total profit of the supply chain $E\left(\Pi^{M}\right)$ and the expected profit of the manufacturer and retailer $E\left(\Pi_{1}^{M}\right), E\left(\Pi_{2}^{M}\right)$ can be obtained.

3.2.3. Balanced Supply Chain System (Type V). When the manufacturer and the retailer are in the same position, neither the manufacturer nor the retailer can dominate the market. Since then, both sides do not know the response function of each other and can only make decisions at the same time. At this time, the manufacturer directly determines the wholesale price $\omega$ and the recycling price $p_{2}$, and the retailer directly determines the retail price $p$ and the recycling price $p_{1}, p_{3}$.

As in the case of retailers leading the supply chain, we introduce marginal returns $m_{1}$ and $m_{2}$ such that $p-\omega=m_{1}, p_{2}-p_{1}=m_{2} . \quad p=\omega+m_{1}, p_{2}=p_{1}+m_{2} \quad$ is substituted into the profit function of the manufacturer and the retailer. Calculate the first derivative of $E\left(\Pi_{2}\right)$ to $p$ and $p_{1}$ and the first derivative of $E\left(\Pi_{1}\right)$ to $p$ and $p_{1}, p_{3}$ :

$$
\left\{\begin{array}{l}
\frac{\partial E\left(\Pi_{1}\right)}{\partial \omega}=a+b\left(c_{1}-\omega\right)-b\left(m_{1}+\omega\right)+\mu=0 \\
\frac{\partial E\left(\Pi_{1}\right)}{\partial p_{2}}=-\lambda c+d\left(m_{2}-p_{2}\right)+r\left(2 p_{3}+t-\delta-p_{2}+m_{2}\right)+\left(\delta-p_{2}\right)(d+\beta)=0 \\
\frac{\partial E\left(\Pi_{1}\right)}{\partial p_{3}}=c(\lambda-1)-d p_{3}-\beta\left(\delta-p_{2}-p_{1}+p_{3}\right)-(d+\beta)\left(p_{3}+t-\delta\right)=0, \\
\frac{\partial E\left(\Pi_{2}\right)}{\partial p}=a-b p-b(p-\omega)+\mu=0, \\
\frac{\partial E\left(\Pi_{2}\right)}{\partial p_{1}}=-\lambda c-d p_{1}-\beta\left(p_{1}-p_{3}\right) d p_{1}-(d+\beta)\left(p_{1}-p_{2}+t\right)=0 .
\end{array}\right.
$$

By solving equations (15), the optimal pricing strategies of the manufacturers and the retailers can be obtained:

$$
\left\{\begin{array}{l}
\omega^{V}=\frac{a+2 b c_{1}+\mu}{3 b}, \\
p^{V}=\frac{2 a+b c_{1}+2 \mu}{3 b}, \\
p_{1}^{V}=\frac{3 \beta(d+\beta) B-2\left[\beta^{2}-(d+\beta)^{2}\right](\lambda c+d t+\beta t)-\left[\beta^{2}-(d+\beta)^{2}\right](\delta d-\lambda c+\beta t)}{-6 d(d+\beta)(d+2 \beta)}, \\
p_{2}^{V}=\frac{3 \beta(d+\beta) B+\left[\beta^{2}-(d+\beta)^{2}\right](-\lambda c+d t+\beta t)+2\left[\beta^{2}-(\beta+d)^{2}\right](\lambda c+\delta d+\beta t)}{-6 d(d+\beta)(d+2 \beta)} \\
p_{3}^{V}=\frac{-\beta(-\lambda c+\delta d+\beta t)+(d+\beta)(-\lambda c+c-\delta d+d t+\beta t)}{-2 d(d+2 \beta)},
\end{array}\right.
$$


where $B=-\lambda c+c-\delta d+d t+\beta t$. By substituting formula (16) into the profit function, the gross profit of the supply chain $E\left(\Pi^{M}\right)$ and the expected profit of the manufacturer and retailer $E\left(\Pi_{1}^{M}\right), E\left(\Pi_{2}^{M}\right)$ can be obtained.

Conclusion 1. Under asymmetric power, the wholesale price of the product satisfies $\omega^{M}>\omega^{V}>\omega^{R}$, and the retail price satisfies $p^{M}=p^{R}>p^{V}>p^{C}$.

Proof. $\omega^{M}-\omega^{V}=\left(a-b c_{1}+\mu / 6 b\right)>0, \omega^{V}-\omega^{R}=\left(a-b c_{1}+\right.$ $\mu / 12 b)>0$; according to the calculation results of the above model, it is easy to prove that $p^{M}=p^{R} \cdot p^{M}-p^{V}=$ $\left(a-b c_{1}+\mu / 12 b\right)>0$, and $p^{V}-p^{C}=\left(a-b c_{1}+\mu / 6 b\right)>0$.

Conclusion 1 shows that, in the forward supply chain, the asymmetric power of supply chain will influence the decision-making behavior. With the increasing power of the manufacturers, they will increase the wholesale price of products to obtain a larger proportion of the total profit.

Conclusion 2. Under asymmetric power, the recycling price of supply chain satisfies $p_{1}^{C}>p_{1}^{V}>p_{1}^{M}=p_{1}^{R}, p_{2}^{R}>p_{2}^{V}>p_{2}^{M}$, $p_{3}^{C}=p_{3}^{V}=p_{3}^{M}=p_{3}^{R}$.

Proof. According to the calculation results of the above model, it is proved that $p_{1}^{M}=p_{1}^{R}, p_{3}^{C}=p_{3}^{V}=p_{3}^{M}=p_{3}^{R}$. $p_{1}^{M}=p_{1}^{R}, p_{3}^{C}=p_{3}^{V}=p_{3}^{M}=p_{3}^{R} \cdot p_{1}^{C}-p_{1}^{V}=(\lambda c+d(\delta-t) / 6$ $(d+\beta))>0, p_{1}^{V}-p_{1}^{M}=(\lambda c+d(\delta-t) / 12(d+\beta))>0$, and $p_{2}^{R}-p_{2}^{V}=(\lambda c+d(\delta-t) / 12(d+\beta))>0, p_{2}^{V}-p_{2}^{R}=(\lambda c+d$ $(\delta-t) / 6(d+\beta))>0$.

Conclusion 2 shows that the asymmetric power of supply chain will affect the decision-making behavior of reverse supply chain. With the increasing power of the retailers, they will increase the recycling price of products to obtain a larger proportion of the total profit of the supply chain. Conclusions 1 and 2 show that the pricing strategy of supply chain is the result of competition among supply chain forces.

Conclusion 3. Under asymmetric power, the total profit satisfies $\Pi^{C}>\Pi^{V}>\Pi^{M}=\Pi^{R}$.

Proof. According to the results of the model, it is easy to prove $\quad \Pi^{M}=\Pi^{R} . \quad \Pi^{C}-\Pi^{V}=\left(\lambda^{2} b c^{2}+b d^{2}(\delta-t)^{2}+\right.$ $\left.2 \lambda b c d(\delta-t)+(d+\beta)\left(a-b c_{1}+\mu\right)^{2} / 16 b(d+\beta)\right)>0 \quad$ and $0<\Pi^{C}-\Pi^{V}=(4 / 9)\left(\Pi^{C}-\Pi^{M}\right)<\Pi^{C}-\Pi^{M}$.

Conclusion 3 shows that the asymmetric power of supply chain will affect the total profit of supply chain, and the total profit of supply chain under asymmetric power is always less than that under centralized decision-making, so the supply chain is in an uncoordinated state under decentralized decision-making.

3.3. Supply Chain Coordination Contract Design. Based on the above research, it can be concluded that, due to the existence of "double marginalization" problem, the total profit of supply chain under decentralized decision is always less than that under centralized decision. Therefore, this paper uses two-tariff contract to coordinate the supply chain system. The principle of coordination is that the profits of manufacturers and retailers after coordination are not less than the profits of each part in decentralized decision-making.

Two-tariff contract is used to coordinate the supply chain, so as to realize the reasonable distribution of the interests of both sides of the game. At this time, the coordination steps are as follows: the manufacturer sells the products to the retailer at the wholesale price $\omega$ and recycles the waste products from the retailer at the price of $p_{2}$. In order to ensure the effective implementation of the contract, the retailer should pay the transfer cost $L$ to the manufacturer, which is determined by bargaining between the two sides of the game. The problem can be described as follows:

$$
\text { s.t. }\left\{\begin{array}{l}
E\left(\left(\overline{\Pi_{1}}\right)\right)=\left(\omega-c_{1}\right) Q+\left(\delta-p_{2}\right) q_{1}+\left(\delta-p_{3}-t\right) q_{2}+F, \\
E\left(\overline{\Pi_{2}}\right)=(p-\omega) Q+\left(p_{2}-p_{1}\right) q_{1}-t q_{1}-F, \\
\overline{\Pi_{i}} \geq \Pi_{i}^{*}(i=1,2), \\
\bar{p}=\operatorname{argmax} E\left(\overline{\Pi_{2}}\right), \\
\overline{p_{1}}=\operatorname{argmax} E\left(\overline{\Pi_{2}}\right), \\
\overline{p_{3}}=\operatorname{argmax} E\left(\overline{\Pi_{2}}\right),
\end{array}\right.
$$

assuming $E\left(\overline{\Pi_{1}}\right)=\varphi E\left(\Pi^{C}\right)$, and we get the following results:

$$
\begin{aligned}
& \left(\omega-c_{1}\right) Q+\left(\delta-p_{2}\right) q_{1}+\left(\delta-p_{3}-t\right) q_{2}+F \\
& \quad=\varphi\left[\left(p-c_{1}\right) Q+\left(\delta-p_{1}\right) q_{1}+\left(\delta-p_{3}-t\right) q_{2}-t q_{1}\right],
\end{aligned}
$$

$$
\begin{aligned}
& \text { Let }\left\{\begin{array}{l}
\left(\omega-c_{1}\right) Q=\varphi\left(p-c_{1}\right) Q \\
\left(\delta-p_{2}\right) q_{1}=\varphi\left(\delta-p_{1}\right) q_{1}, \text { and the solution is } \\
F=-\varphi t q_{1}
\end{array}\right. \\
& \left\{\begin{array}{l}
\omega=\varphi\left(p-c_{1}\right)+c_{1} \\
p_{2}=\delta+\varphi\left(p_{1}-\delta\right) \\
F=-\varphi t\left[\lambda c+d p_{1}+\beta\left(p_{1}-p_{3}\right)\right]
\end{array}\right.
\end{aligned}
$$

Substituting $p^{C}, p_{1}^{C}$, and $p_{3}^{C}$ under centralized decision into the above formula, we can get the following results: 


$$
\left\{\begin{array}{l}
\omega=\frac{\varphi\left(a-b c_{1}+\mu\right)+2 b c_{1}}{2 b}, \\
p_{2}=\frac{-\varphi c(\lambda d+\beta)-\varphi \delta d^{2}+2 \delta d(d-\varphi \beta+2 \beta)+\varphi d t(d+2 \beta)}{2 d(d+2 \beta)}, \\
F=\frac{\varphi t(-\lambda c-d \delta+d t)}{2} .
\end{array}\right.
$$

Under different decentralized decisions, wholesale price $\omega$, recycling price $p_{2}$, and transfer cost $L$ to the manufacturer change with the proportion of manufacturer's profit to total supply chain profit $\varphi$. When $L>0$, it indicates that the retailer has to pay the transfer cost to the manufacturer; when $L<0$, it indicates that the manufacturer needs to pay the transfer cost to the retailer. At this time, the retailer determines the price according to the pricing strategy in the centralized decision model. Because $E\left(\overline{\Pi_{1}}\right)=(1-\varphi) E\left(\Pi^{C}\right)$ and $E\left(\overline{\Pi_{1}}\right)+E\left(\left(\overline{\Pi_{2}}\right)\right)=E\left(\Pi^{C}\right)$, the closed-loop supply chain is coordinated.

\section{Numerical Simulation}

The above model mainly uses mathematical model to study the influence of different decision-making modes of supply chain system and asymmetric power of game parties on the profit of the manufacturer, the retailer, and the supply chain system. Because of the large number of parameters and the complexity of the model, the calculation results cannot be very intuitive.

In order to further study the impact of batch wholesale price $\omega$, recycling price $p_{2}$, and transfer cost $L$ on the coordination effect, as well as the impact of channel competition coefficient $\lambda$ and consumer sensitivity coefficient $\beta$ on the total profit of supply chain, the nonmain parameters in the above model are assigned and mapped with Python, which can make the research results more intuitive. Relevant parameter settings are shown in Table 1.

Because the influence trends of channel competition coefficient and consumer's sensitivity coefficient to the price difference of different channels on the total profit of supply chain are roughly the same under centralized decision and decentralized decision-making, only centralized decisionmaking is analyzed. Under the influence of channel competition coefficient and consumer sensitivity coefficient to price difference, the change trend of total profit of supply chain is shown in Figure 2. It can be seen from Figure 2 that, with the increase of channel competition coefficient, the total profit of supply chain presents a "U-shaped" pattern; that is, when the competition of recycling channel is more intense, the total profit of supply chain is lower; with the increase of consumer's sensitivity coefficient of price difference, the total profit of supply chain shows a downward trend.

In the case of manufacturer-dominated supply chain, the profit margin function of the manufacturer and the retailer before and after coordination is obtained by substituting relevant parameters into the expected profit function of the manufacturer and the retailer before and after coordination: $\left\{\begin{array}{l}\Delta \Pi_{1}=L-14 p_{2}+91 \omega-711.2 \\ \Delta \Pi_{2}=-L+14 p_{2}-91 \omega+2445.8\end{array} ;\right.$ if the recycling price $p_{2}=5$, the effect of $\omega$ and $L$ on the coordination effect is shown in Figure 3 when the manufacturer is dominant.

It can be seen from Figure 3 that the change of wholesale price $\omega$ and transfer cost $L$ will lead to the linear change of profit margin between the manufacturer and the retailer before and after coordination. The manufacturer's profit margin is positively correlated with wholesale price $\omega$ and transfer cost $L$, but the retailer's profit margin is negatively correlated with wholesale price $\omega$ and transfer cost $L$ before and after coordination. Therefore, when the manufacturer dominates the supply chain, the manufacturer can increase the wholesale price $\omega$ to obtain a larger proportion of the total profit of the supply chain. From the impact of single factor on the profit margin, the wholesale price $\omega$ has a more obvious impact on the profit margin; that is, compared with the transfer cost $L$, the wholesale price $\omega$ has a greater impact on the coordination effect.

Since the results of type $M$ and type $R$ are similar, this study will not analyze the influence of wholesale price $\omega$ and transfer cost $L$ on coordination effect when the retailers are dominant. The profit margin function of the manufacturer and the retailer before and after coordination can be obtained by substituting the relevant parameters into the expected profit function of the manufacturer and the retailer before and after the coordination under the condition of the potential average force of the manufacturer and the retailer: $\left\{\begin{array}{l}\Delta \Pi_{1}=L-9.3 p_{2}+60.7 \omega-474.1 \\ \Delta \Pi_{2}=-L+9.3 p_{2}-60.7 \omega+1245.1\end{array} ;\right.$ if the recycling price $p_{2}=5$, the effect of $\omega$ and $L$ on the coordination effect is shown in Figure 4 when the manufacturer and the retailer are balanced in power.

It can be seen from Figure 4 that when the manufacturer and the retailer are balanced in power, the impacts of wholesale price $\omega$ and transfer cost $L$ on the profit margin of the manufacturer and the retailer before and after the coordination are roughly the same as those when the manufacturer is dominant; that is, the manufacturer's profit margin is positively correlated with wholesale price $\omega$ and transfer cost $L$ before and after coordination, but the retailer's profit margin is negatively correlated with wholesale price $\omega$ and transfer cost $L$ before and after coordination. Because the profit margin between the manufacturer and the retailer is small under the situation of equal power, the change range of profit caused by the change of wholesale 
TABLE 1: Related parameter values.

\begin{tabular}{lcccccccccccc}
\hline Parameter & $a$ & $b$ & $c$ & $d$ & $t$ & $c_{1}$ & $c_{2}$ & $\delta$ & $\mu$ & $\lambda$ & $\beta$ \\
\hline Values & 400 & 5 & 100 & 2 & 1 & 8 & 4 & 4 & 4 & 0.5 & 0.5 \\
\hline
\end{tabular}

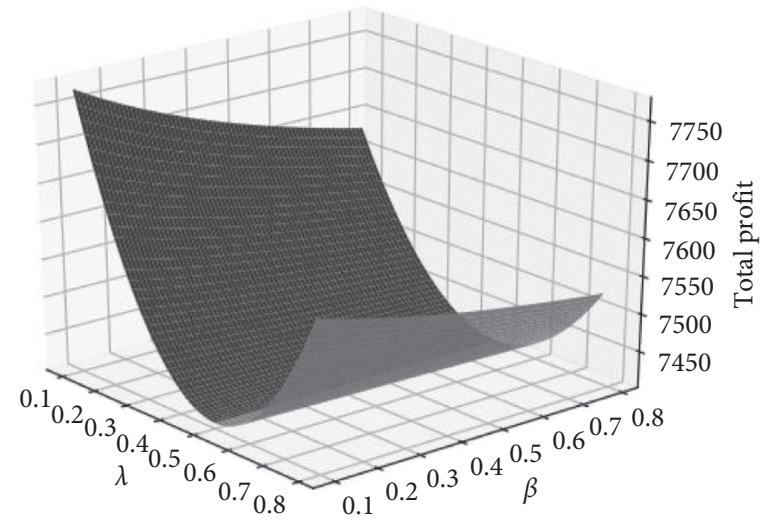

Figure 2: The impact of $\lambda$ and $\beta$ on the total profit of supply chain under centralized decision.

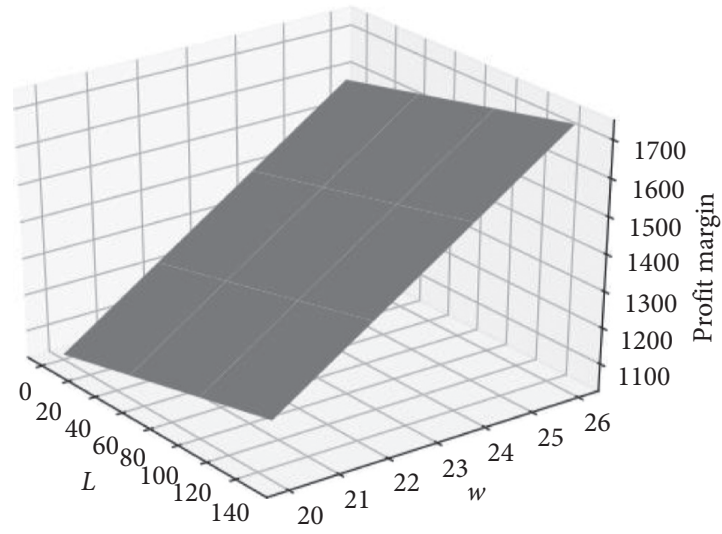

(a)

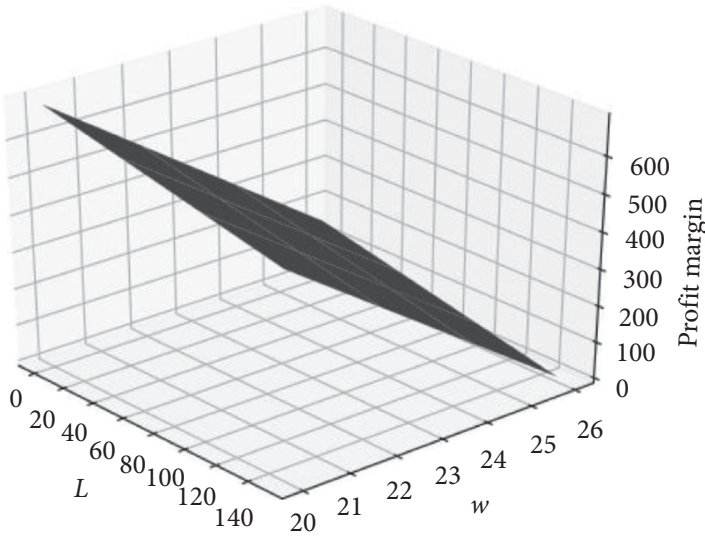

(b)

Figure 3: The effect of $\omega$ and $L$ on the coordination effect when the manufacturer is dominant. (a) Manufacturer. (b) Retailer.

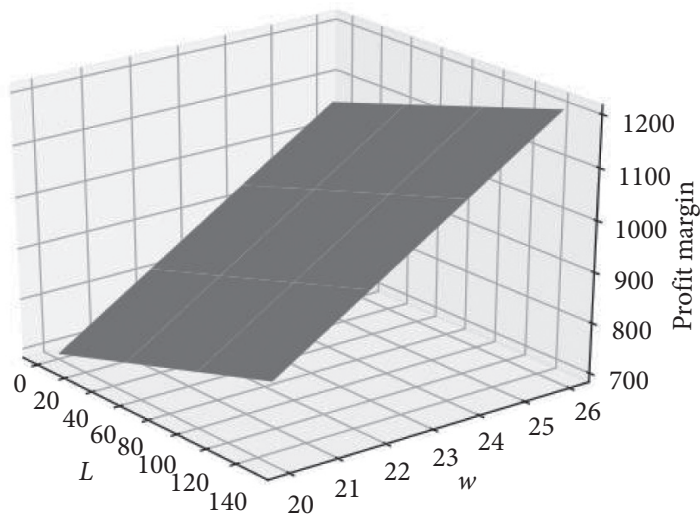

(a)

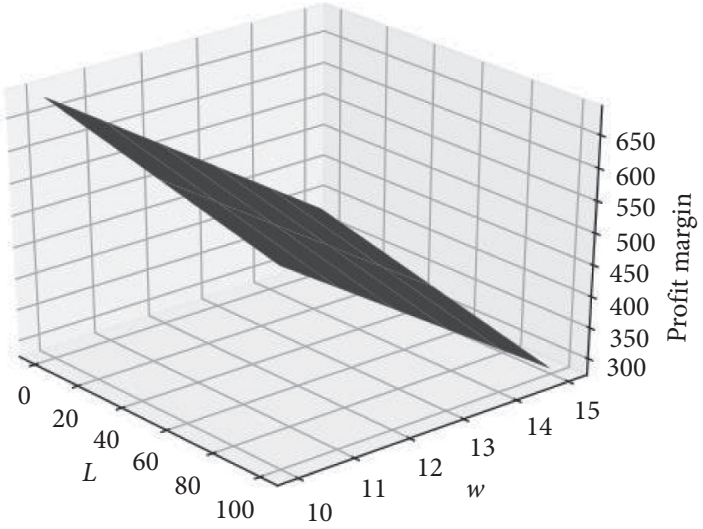

(b)

Figure 4: The effect of $\omega$ and $L$ on the coordination effect when the manufacturer and the retailer are balanced in power. (a) Manufacturer. (b) Retailer. 
price wor transfer cost $L$ unit is smaller than that when the manufacturer is dominant.

\section{Conclusion}

Based on the existing research, this paper studies the pricing strategy and profit distribution of closed-loop supply chain under asymmetric powers, considering the stochastic demand and the double-channel recycling model. It is found that, because of the "double marginalization," the total profit of supply chain is always less than that of supply chain with centralized decision. Therefore, the supply chain under decentralized decision is coordinated by two-tariff contract; that is, different coordination methods are given according to the different proportion of manufacturer's profit to total profit of supply chain. Finally, the effect of wholesale price and transfer cost on coordination effect is studied by numerical simulation. The results show that wholesale price has more influence on coordination effect than transfer cost.

The game decision-making behavior discussed in this paper is carried out under the premise of information symmetry, but, in the market economy, the information is often asymmetric, so, in the future research, we should consider the information transparency parameter in the modeling process. In addition, this paper assumes that there is no difference in consumers' preference for new products and remanufactured products, but consumers tend to prefer new products in real life, so we need to further consider the price difference between the two products in future research.

\section{Managerial Implication}

Through the research on pricing strategy and coordination mechanism of dual-channel closed-loop supply chain under asymmetric power, we can find that supply chain collaborative management mode greatly reduces the operation cost of supply chain, improves the response speed to customer demand, better maintains customer loyalty, and brings rich returns for both sides. Therefore, supply chain enterprises should set up a common strategic goal, strengthen their own core competence, realize complementary advantages, and effectively coordinate the production, operation, and management activities of member enterprises in the supply chain by strengthening the internal management of the supply chain.

\section{Data Availability}

The data used to support the findings of this study are available from the corresponding author upon request.

\section{Conflicts of Interest}

The authors declare that there are no conflicts of interest regarding the publication of this paper.

\section{Acknowledgments}

The finding was sponsored by the National Social Science Fund of China (Grant no. 18CGL015).

\section{References}

[1] Z. Liu, L. L. Lang, B. Hu et al., "Emission reduction decision of agricultural supply chain considering carbon tax and investment cooperation," Journal of Cleaner Production, vol. 294, p. 8, Article ID 126305, 2021.

[2] B.-F. Liao and B.-Y. Li, "A marketing strategy in a closed-loop supply chain with loss-averse consumers," Mathematical Problems in Engineering, vol. 2018, Article ID 2560153, 9 pages, 2018.

[3] Z. Liu, B. Hu, and B. T. Huang, "Decision optimization of lowcarbon dual-channel supply chain of auto parts based on smart city architecture"” Complexity, vol. 5, pp. 1-14, 2020.

[4] D. Yang and L. W. Xue, "Interest coordination of dual-recovery closed-loop supply chains dominated by dual-channels retailers," Journal of Wuhan University of Technology (Transportation Science \& Engineering), vol. 43, no. 6, pp. 1140-1146, 2019.

[5] J. H. Zhao and J. Lin, "Pricing models of closed-loop supply chain under different subsidy policies"' Journal of Industrial Engineering and Engineering Management, vol. 31, no. 1, pp. 85-92, 2017.

[6] X. D. Zhu, B. B. Wu, and Z. Wang, "Closed-loop supply chain pricing strategy and coordination mechanism under the different of dual-channel recycling cost," Chinese Journal of Management Science, vol. 25, no. 12, pp. 188-196, 2017.

[7] B. R. Zheng, C. Yang, and J. Yang, "The effect of CSR investment on pricing and coordination strategies in closedloop supply chains"” Chinese Journal of Management Science, vol. 26, no. 10, pp. 64-78, 2018.

[8] F. M. Yao and C. X. Teng, "Decision models of closed-loop supply chain with dominant retailer considering fairness concern"' Control and Decision, vol. 32, no. 1, pp. 117-123, 2017.

[9] A. Haddadsisakht and S. M. Ryan, "Closed-loop supply chain network design with multiple transportation modes under stochastic demand and uncertain carbon tax," International Journal of Production Economics, vol. 195, pp. 118-131, 2017.

[10] N. M. Modak, N. Modak, S. Panda, and S. S. Sana, "Analyzing structure of two-echelon closed-loop supply chain for pricing, quality and recycling management," Journal of Cleaner Production, vol. 171, pp. 512-528, 2018.

[11] S. Navid, M. F. Amir, and H. K. Mostafa, "Sustainable tire closed-loop supply chain network design: hybrid metaheuristic algorithms for large-scale networks," Journal of Cleaner Production, vol. 196, pp. 272-296, 2018.

[12] Z. Liu, S. Chen, B. Hu, M. Zhou, and Y. Zhao, "Research on staged pricing model and simulation of intelligent urban transportation," IEEE Access, vol. 7, pp. 141404-141413, 2019.

[13] D. H. Lee, "Pricing decisions in a competitive closed-loop supply chain with duopolistic recyclers," Mathematical Problems in Engineering, vol. 2020, Article ID 5750370, 22 pages, 2020.

[14] Z. Liu, H. X. Guo, H. Guo et al., "Research on the optimized route of cold chain logistics transportation of fresh products in context of energy-saving and emission reduction," Mathematical Biosciences and Engineering, vol. 18, no. 2, pp. 1926-1940, 2021.

[15] M. F. Li and J. M. Xue, "Performance analysis of manufacturer collecting closed-loop supply chain under different channel power structures," Control and Decision, vol. 31, no. 11, pp. 2095-2100, 2016.

[16] P. Gao, J. G. Du, J. J. Nie, and Y. M. Lu, "Impact of different structure on technological innovation strategy of 
remanufacturing supply chain," Chinese Journal of Management, vol. 13, no. 10, pp. 1563-1670, 2016.

[17] X. R. Li, Y. Y. Liu, and M. N. Yu, "A research on the closedloop supply chain decision making considering free riding behavior under different authority structure"' Science Research Management, vol. 39, no. 3, pp. 45-58, 2018.

[18] D. D. Fan and Q. Xu, "Decisions of enterprises carbon emission reduction and government subsidy in different power structures," Soft Science, vol. 32, no. 12, pp. 64-70, 2018.

[19] A. A. Taleizadeh, M. S. Moshtagh, and I. Moon, "Optimal decisions of price, quality, effort level and return policy in a three-level closed-loop supply chain based on different game theory approaches," European Journal of Industrial Engineering, vol. 11, no. 4, pp. 486-525, 2017.

[20] D. Lee, "Pricing decisions in a competitive closed-loop supply chain with duopolistic recyclers," Mathematical Problems in Engineering, vol. 2020, Article ID 5750370, 21 pages, 2020.

[21] Y. Ranjbar, H. Sahebi, J. Ashayeri, and A. Teymouri, "A competitive dual recycling channel in a three-level closed loop supply chain under different power structures: pricing and collecting decisions"' Journal of Cleaner Production, vol. 272, pp. 1-20, 2020.

[22] Z. Liu, B. Hu, Y. Zhao et al., "Research on intelligent decision of low carbon supply chain based on carbon tax constraints in human-driven edge computing," IEEE Access, vol. 8, pp. 48264-48273, 2020. 